This is a non-peer reviewed pre-print submitted to EarthArXiv.

Subsequent peer-reviewed versions of this manuscript may have slightly different content.

The author welcome feedback.

Please contact Sandy H.S. Herho (herho@umd.edu) regarding this manuscript's content. 


\title{
LONG-TERM HYDROMETEOROLOGICAL TIME-SERIES ANALYSIS OVER THE CENTRAL HIGHLANDS OF WEST PAPUA
}

\author{
SANDY H. S. HERHO ${ }^{1}$ \\ ${ }^{1}$ Department of Geology, \\ College of Computer, Mathematics and Natural Sciences, \\ University of Maryland, \\ College Park, MD, USA 20742 \\ E-mail: herho@umd.edu \\ Received: April 9, 2021 (EarthArxiv v2.0 r2018a)
}

\begin{abstract}
This article presents a novel data-driven approach for studying longterm temporal rainfall pattern over the central highlands of West Papua, Indonesia. Using wavelet transforms we found indications of negative temporal relationship of El Niño - Southern Oscillation (ENSO) and 12-month Standarized Precipitation Index (SPI-12). Based on this causal relationship, we perform dynamic causality modeling using the Nonlinear Autoregressive with Exogenous input (NARX) model to predict SPI-12 using the Multivariate ENSO Index (MEI) as an attribute variable. As a result, this dynamic neural network model is able to capture common features in the SPI-12 time series. This study has a profound impact for the future development of datadriven precipitation models for areas with complex topography in Indonesian Maritime Continent (IMC).

Key words: ENSO, NARX, SPI, wavelet transform.
\end{abstract}

\section{INTRODUCTION}

The central highlands of West Papua is part of the province of Papua, which is the easternmost province of Indonesia (Figure 1). This region has a complex landscape with rugged and hilly terrain. Some of the highest peaks in Indonesia, such as Carstensz Pyramid (5030 m.a.s.l), Trikora Peak (4730 masl), Yamin Peak (4595 m.a.s.l), and Mandala Peak (4700 m.a.s.l) are also located in the central highlands of West Papua. This complex geomorphological appearance is an expression of the geological and tectonic conditions that have occurred in that place. According to [1] the island of Papua was formed from a process of subduction between the Australian Plate and the Pacific Plate. The convergent process and deformation of these two plates began in the Eocene and continues to the present [2]. The Australian Plate, which is under the Arafura Sea and extends to the north, is the base of the southern part of the central highlands of West Papua, where the base layer is composed of sedimentary rocks within the ages ranging from Paleozoic to Mid-Quaternary [3].

The central highlands of West Papua stretches from the equator to $12^{\circ} \mathrm{S}$. This 
area can be classified as a tropical region dominated seasonally by the monsoonal asymmetric cycle, like most areas in the Indonesian Maritime Continent (IMC) [4, 5]. Apart from monsoonal influences, as in other areas in the IMC, central highlands of West Papua there are also local influences, such as mountain deflection and local warming which control rainfall circulation in this area [6]. In addition, El Niño Southern Oscillation (ENSO) also has an impact on seasonal rainfall conditions in Papua, El Niño events can reduce rainfall in the area [7]. This region experiences variations in precipitation between $2500-4500 \mathrm{~mm} / \mathrm{year}$ with the number of rainy days varying from 148 to 175 rainy days/year with average surface air temperatures of $29^{\circ} \mathrm{C}$ to $31.8^{\circ} \mathrm{C}$ and relative humidity varying between $79 \%$ to $81 \%$. Thus, the central highlands of Papua is one of the wettest areas in the IMC [8].

Studies that discuss the characteristics of rainfall in the Papua region are still difficult to find. This can be due to the complex regional topography in this area which makes it difficult to study it using a numerical approaches [9]. Besides, this can also be caused by aerial coverage of rain gauges and radar networks owned by the Indonesian Agency for Meteorology Climatology and Geophysics (BMKG) [10]. To solve this problem, we offer a solution by using a data-driven approach [11] by utilizing ERA5 monthly averaged data on single levels [12] to reveal the characteristics and predictability of long-term precipitation time series over the central highlands of Papua.

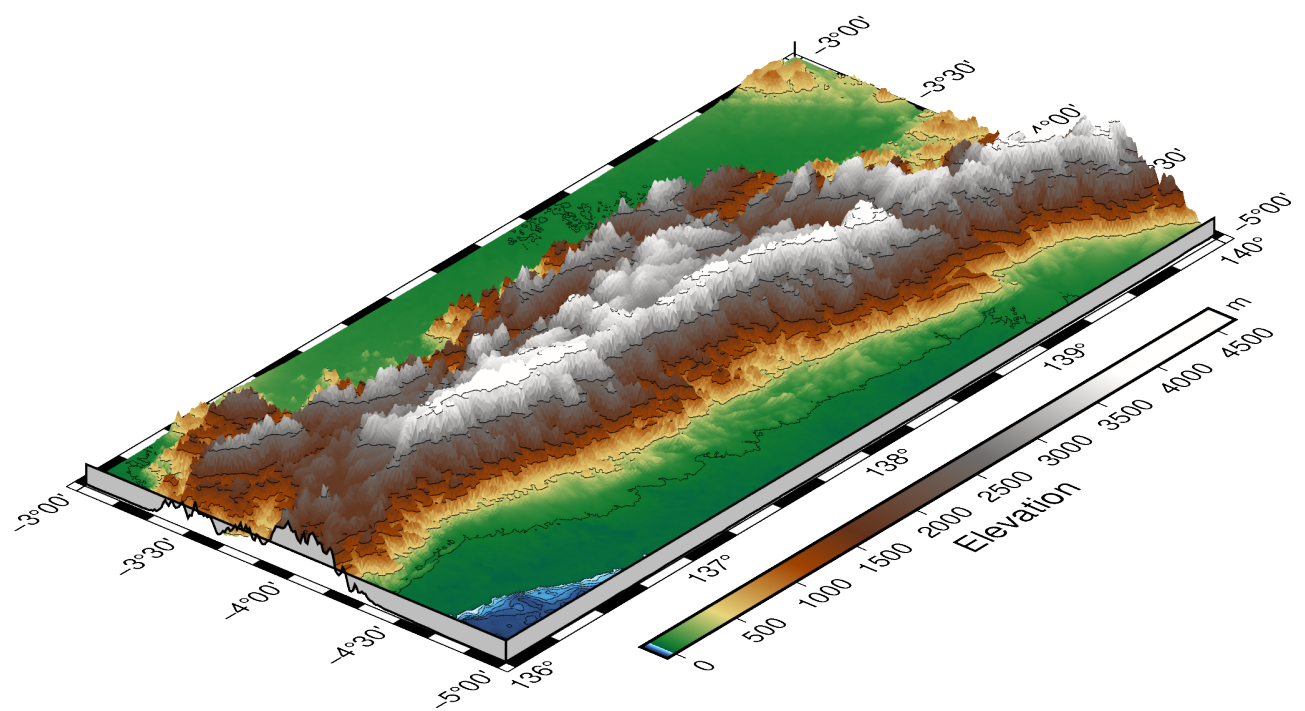

Fig. 1 - Digital Elevation Model (DEM) of the central highlands of West Papua (rendered using PyGMT [13]). 


\section{LONG-TERM DROUGHT / PLUVIAL TIME-SERIES RECONSTRUCTION}

In this part, we reconstruct long-term meteorological drought/pluvial events over the central highlands of West Papua. We use SPI-12 [14, 15] as the standard for measuring long-term meteorological drought/pluvial events that successfully used to reconstruct drought throughout the past millennium period over the IMC [16].

The first step we take, is to calculate the spatial average of land precipitation over the central highlands of West Papua using the ERA5 monthly averaged data on single levels [12]. Spatial average of a precipitation field $\bar{p}(\phi, \theta, t)$ on a sphere [17] is mathematically defined in the equation (1),

$$
\bar{p}(t)=\frac{1}{4 \pi} \iint p(\phi, \theta, t) \cos (\phi) d \phi d \theta
$$

, where $\phi$ is latitude, $\theta$ is longitude, and $t$ is time. To handle the gridded dataset, a discretized form of equation (1) is needed.The discrete form of equation (1) for a grid resolution $\Delta \phi \times \Delta \theta$ is defined in equation (2),

$$
\bar{p}(t)=\sum_{i, j} p(i, j, t) \frac{\cos \left(\phi_{i, j}\right) \Delta \phi \Delta \theta}{4 \pi}
$$

, where $(i, j)$ are coordinate indices for each the grid box of precipitation data over the central highlands of West Papua, and $\phi$ and $\theta$ are in radian. Since ERA5 precipitation data has a spatial resolution of $0.25^{\circ} \times 0.25^{\circ}$, then $\Delta \phi=\Delta \theta=(0.25 / 180) \pi=$ $\pi / 720$. By substituting this information into equation (2), the following equation is obtained,

$$
\bar{p}(t)=\sum_{i, j} p(i, j, t) \frac{\cos \left(\phi_{i, j}\right)(1 / 720)^{2}}{4}
$$

We solve the calculation in the equation (3) using the built-in function in the xarray library [18] in the Python computational environment.

The calculation result of equation (3) is the spatial average of monthly precipitation time-series shown in Figure 2. Figure 2 shows that rainfall events occurred in each month in this period of study. To see the pattern of monthly rainfall, we average the data for each month, as shown in Figure 3. It can be seen in Figure 3 that the monthly rainfall pattern in the central highlands of West Papua has one peak and one trough, which corresponds to the rainfall pattern in Region A [19] with a shift in the onset of wet and dry seasons which is thought to be caused by other local factors. The seasonal rainfall patterns over the central highlands of West Papua (Figure 3) seem to follow an asymmetric pattern between boreal summer and winter and between boreal spring and fall.

The spatial average of monthly precipitation is then used as input for the calculation of SPI-12. SPI-12 itself is the comparison of rainfall for 12 consecutive 


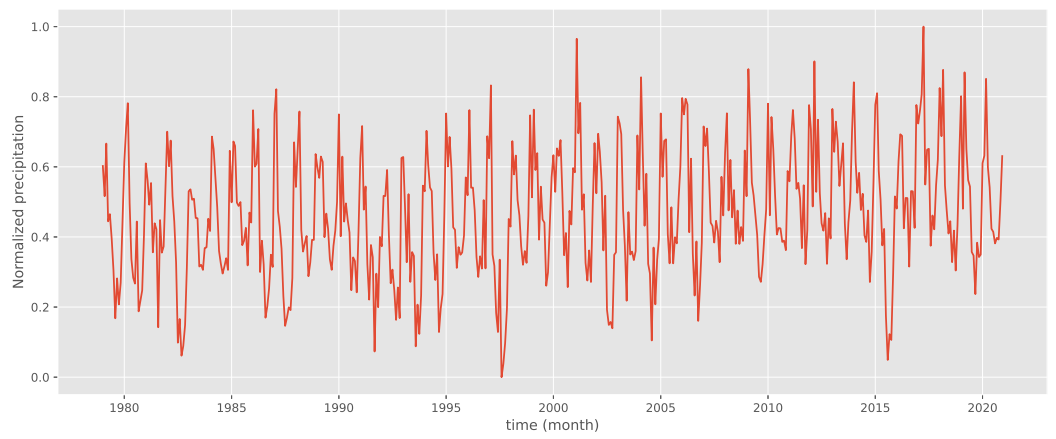

Fig. 2 - Variations in the normalized monthly precipitation data from ERA5 over the central highlands of West Papua from January 1979 to December 2020.

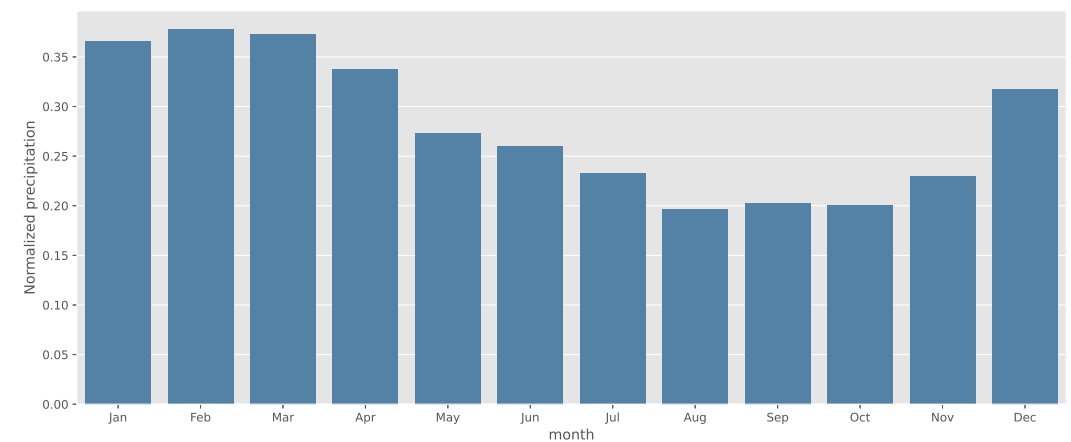

Fig. 3 - Normalized average monthly precipitation over the central highlands of Papua.

months with the same 12 consecutive months from previous years. The SPI on this time scale reflects long-term rainfall patterns $[14,15]$.The time scale is the cumulative of previous periods that may be above or below normal. SPI on this scale can be related to streamflows, reservoir conditions, and even groundwater content. In several countries the SPI-12 is most closely related to the Palmer Drought Severity Index (PDSI) and it is also possible that both indices reflect the same conditions [20].

SPI is calculated using statistical methods as follows,

$$
G(x)=\int_{0}^{x} g(x, \hat{\alpha}, \hat{\beta}) d x=\frac{1}{\hat{\beta}^{\hat{\alpha}} \Gamma(\hat{\alpha})} \int_{0}^{x} x^{\hat{\alpha}-1} e^{-x / \hat{\beta}}
$$

, where $\alpha$ is a shape parameter, $\beta$ is a scale parameter, $\Gamma(\alpha)$ is a gamma function, and $x$ is precipitation values. Equation (4) applies if $x>0$ (otherwise $g(x, \hat{\alpha}, \hat{\beta})=0$, 
which in this case applies to precipitation data which are always within the range $(0,+\infty)$. In order to match the gamma distribution with precipitation data, it is necessary to estimate the $\alpha$ and $\beta$ parameters using the maximum likelihood approximation which is defined as follows,

$$
\hat{\alpha}=\frac{1}{4 A}\left(1+\sqrt{\frac{4 A}{3}}\right)
$$

, where $A$ is defined by equation (7),

$$
\hat{\beta}=\frac{\bar{x}}{\hat{\alpha}}
$$

$$
A=\ln (\bar{x})-\frac{\sum \ln (x)}{n}
$$

, where $n$ is the number of observations. For $\hat{\alpha}>0, \Gamma(\hat{\alpha})$ is defined by equation (8),

$$
\Gamma(\hat{\alpha})=\int_{0}^{+\infty} x^{(\hat{\alpha}-1)} e^{-x} d x
$$

The gamma distribution is undefined for $x=0$ and $q=P(x=0)>0$, where $q$ is the probability of zero percipitation. Therefore the cumulative probability distribution is defined by equation (9),

$$
H(x)=q+(1-q) G(x)
$$

The gamma distribution $G(x)$ is then converted to be a normal standard with zero mean and standard deviation of one, so that the SPI index $Z$ is obtained using equation (10),

$$
Z= \begin{cases}-t-\frac{c_{0}+c_{1} t+c_{2} t^{2}}{1+d_{1} t+d_{2} t^{2}+d_{3} t^{3}}, & \text { for } 0<H(x) \leq 0.5 \\ t-\frac{c_{0}+c_{1} t+c_{2} t^{2}}{1+d_{1} t+d_{2} t^{2}+d_{3} t^{3}}, & \text { for } 0.5<H(x)<1\end{cases}
$$

, where $t$ is defined by equation (11),

$$
t= \begin{cases}\sqrt{\ln \left(\frac{1}{(H(x))^{2}}\right)}, & \text { for } 0<H(x) \leq 0.5 \\ \sqrt{\ln \left(\frac{1}{(1-H(x))^{2}}\right)}, & \text { for } 0.5<H(x)<1\end{cases}
$$

, and the constants are defined as follows,

$$
c_{0}=2.515517, c_{1}=0.802853, c_{2}=0.010328, d_{1}=1.432788, d_{2}=0.109269, d_{3}=0.001308
$$

In order to simplify the calculation process, we use the SPEI package [21] in the $\mathrm{R}$ computational environment. The result of the SPI-12 reconstruction for the period January 1980 to December 2020 is shown in Figure 4. 


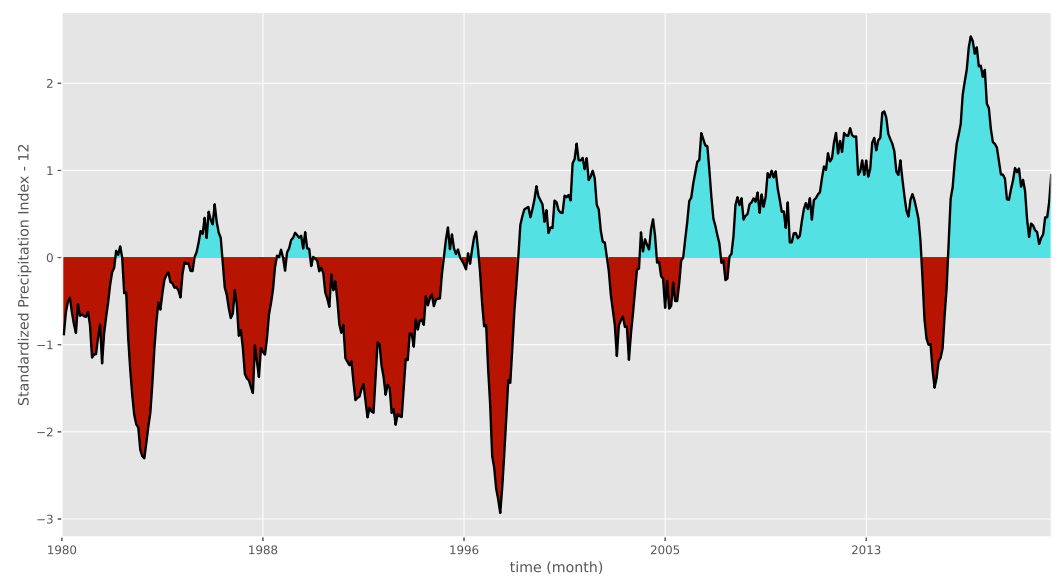

Fig. 4 - SPI values over the central highlands of West Papua from January 1980 to December 2020 with a 12-month time scale. Negative SPI-12 describes dry conditions (red), whereas positive SPI-12 describes wet conditions (blue).

\section{IDENTIFYING ENSO-DRIVEN PATTERN IN SPI-12}

The influence of the ENSO signal in the IMC [7, 10, 22] is a fact that should not be ignored in the analysis of drought/pluvial events in the central highlands of West Papua. In this section we discuss the temporal effect of ENSO, using Multivariate ENSO Index (MEI) [23], on SPI-12. To measure the temporal effect of ENSO on drought/pluvial events over the area of study, we use the popular algorithm for measuring geophysical signal patterns, i.e. wavelet transforms. The advantage of wavelet transforms compared to other power spectrum methods is that they can capture nonlinear signals from time series because they use small wave packets (wavelets) as the base functions which intrinsically have smooth ends, instead of using sine and cosine wave functions [24].

In this study we use an extension of the Morlet wavelet $(\psi)$ [25] to model ENSO and SPI-12 signals, which is defined by,

$$
\psi(t)=\pi^{-\frac{1}{4}} e^{-i \omega_{0} t} e^{-\frac{1}{2} t^{2}}, t=1,2,3, \cdots
$$

, where $t$ is the position where the wavelet operates in a time series with a narrow range of observations.

In general, wavelets have two main components, namely time or position $k$ and frequency $f$. The $k$ parameter has an important role in detecting the exact location of a wavelet by relocating the wavelet over a period of time, while $f$ is useful for monitoring the convex wavelet to localize different frequencies. By transforming $\psi$, 
144 we get the $\psi_{k, f}$ parameter as follows,

$$
\psi_{k, f}(t)=\frac{1}{\sqrt{h}} \psi\left(\frac{t-k}{f}\right), k, f \in \mathbb{R}, f \neq 0
$$

Equation (15) describes the modeling of a time series $x(t)$ into a wavelet transform,

$$
W_{x}(k, f)=\int_{-\infty}^{+\infty} x(t) \frac{1}{\sqrt{f}} \psi\left(\frac{\overline{(t-k)}}{f}\right) d t
$$

The signal power in the time series $x(t)$ itself is measured using the wavelet power spectrum $\operatorname{WPS}_{x}(k, f)$ which is defined as follows,

$$
W P S_{x}(k, f)=\left|W_{x}(k, f)\right|^{2}
$$

In order to simplify the process of calculating the continuous wavelet power spectrum on ENSO and SPI-12 data, we use the PyCWT library [26] in the Python computational environment.

a) Standardized Precipitation Index - 12

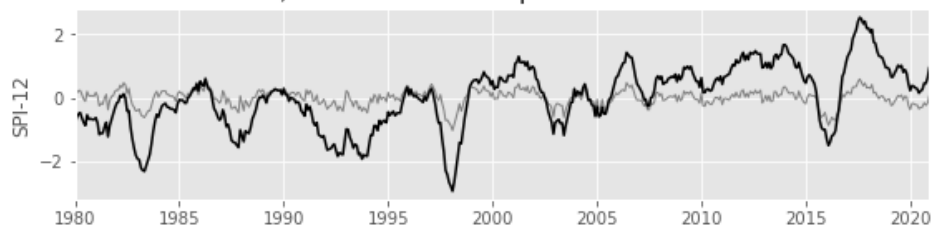

b) SPI-12 Wavelet Power Spectrum (Morlet)

c) Global Wavelet Spectrum

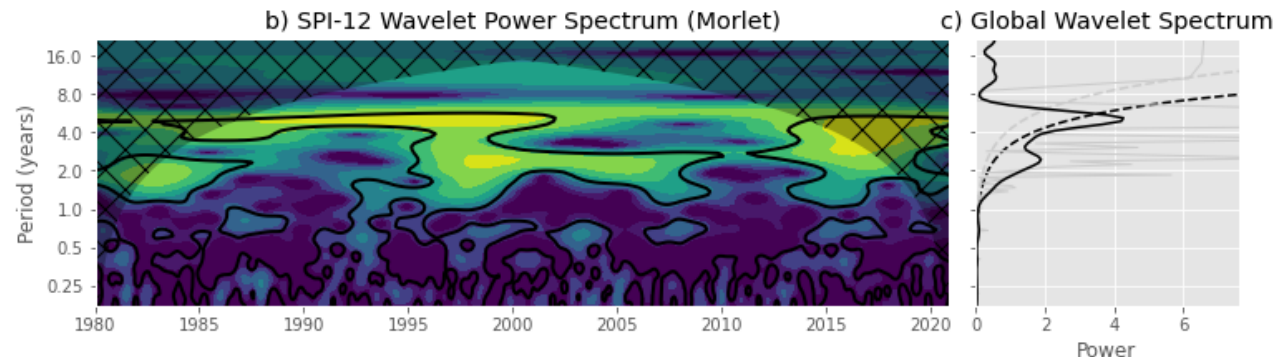

d) 2-8 year scale-averaged power

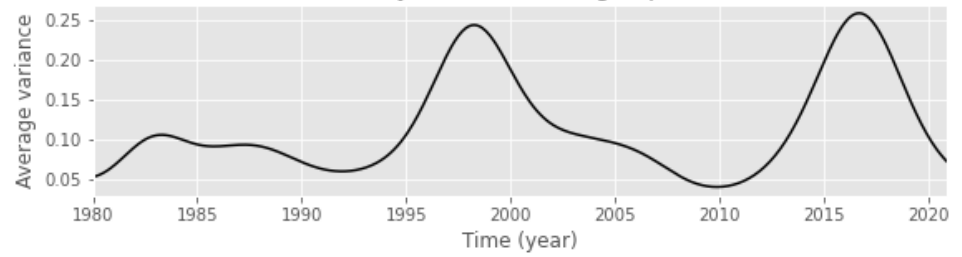

Fig. 5 - Continuous wavelet transform for the SPI-12. These plots clearly shows significant periodicity at $2-8$ year cycle. 
a) Multivariate ENSO Index
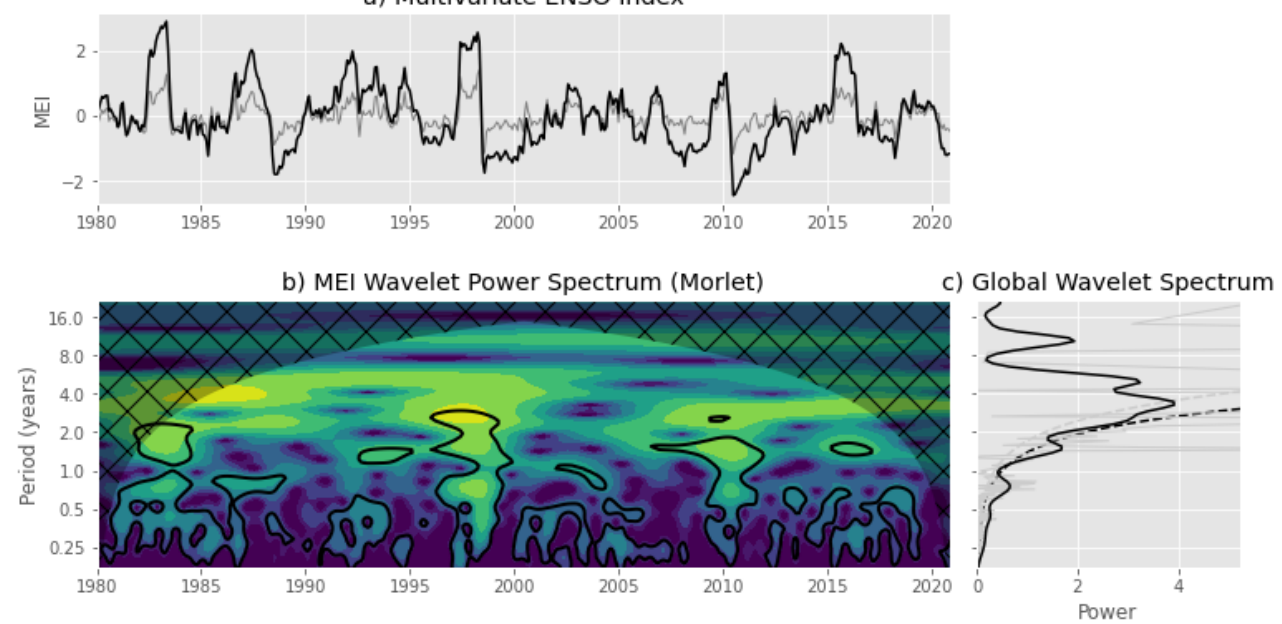

d) 2-8 year scale-averaged power

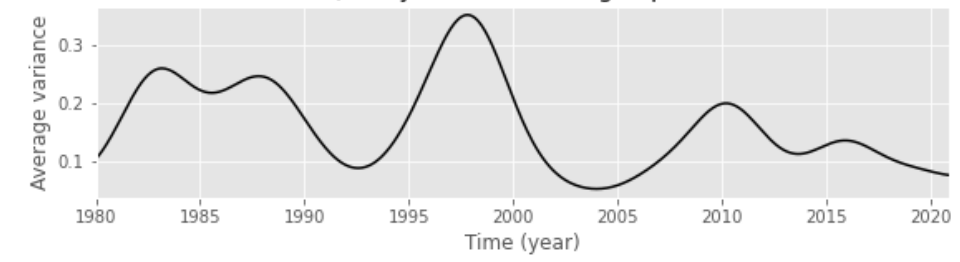

Fig. 6 - Continuous wavelet transform for the MEI. These plots clearly shows significant periodicity at $2-8$ year cycle.

There are similarities of WPS between ENSO (Figure 6) and SPI-12 (Figure 5). However, to measure the relationship between the two quantitatively, I need another mathematical tool, namely the wavelet coherence (WTC). We use WTC to find timefrequency-based causality between two time-series data, in this context MEI. $x(t)$ and SPI-12 $y(t)$. The first step we take is to find the cross wavelet transform (XWT) of the two time-series data (equation (17)),

$$
W_{x y}(k, f)=W_{x}(k, f) \overline{W_{y}(k, f)}
$$

, where $W_{x, y}(k, f)$ is the XWT of the two time-series data. Then to find WTC value, the equation (18) is used as follows,

$$
R^{2}(k, f)=\frac{\left|C\left(f^{-1} W_{x y}(k, f)\right)^{2}\right|}{C\left(f^{-1}\left|W_{x}(k, f)\right|^{2}\right) C\left(f^{-1}\left|W_{y}(k, f)\right|^{2}\right)}
$$

, $C$ parameter shows the time and smoothing process over the duration of time in within the range of $0 \leq R^{2}(k, f) \leq 1$. When $R^{2}(k, f)$ approaches one, a strong correlation can be expected between MEI and SPI-12 (indicated by light yellow color 
surrounded by a black line in the figure 7). Conversely, if $R^{2}(k, f)$ is zero, then there is no correlation between the two variables. To find out the positive or negative correlation of the two time-series data, we use the phase difference equation (equation (19)) as follows,

$$
\phi_{x y}(k, f)=\arctan \left(\frac{\Im\left\{C\left(f^{-1} W_{x y}(k, f)\right)\right\}}{\Re\left\{C\left(f^{-1} W_{x y}(k, f)\right)\right\}}\right)
$$

, where $\Re$ shows the real part and $\Im$ shows the imaginary part. To simplify the WTC calculation process, we use the open source MATLAB ${ }^{\circledR}$ Toolbox by (author?) [27].

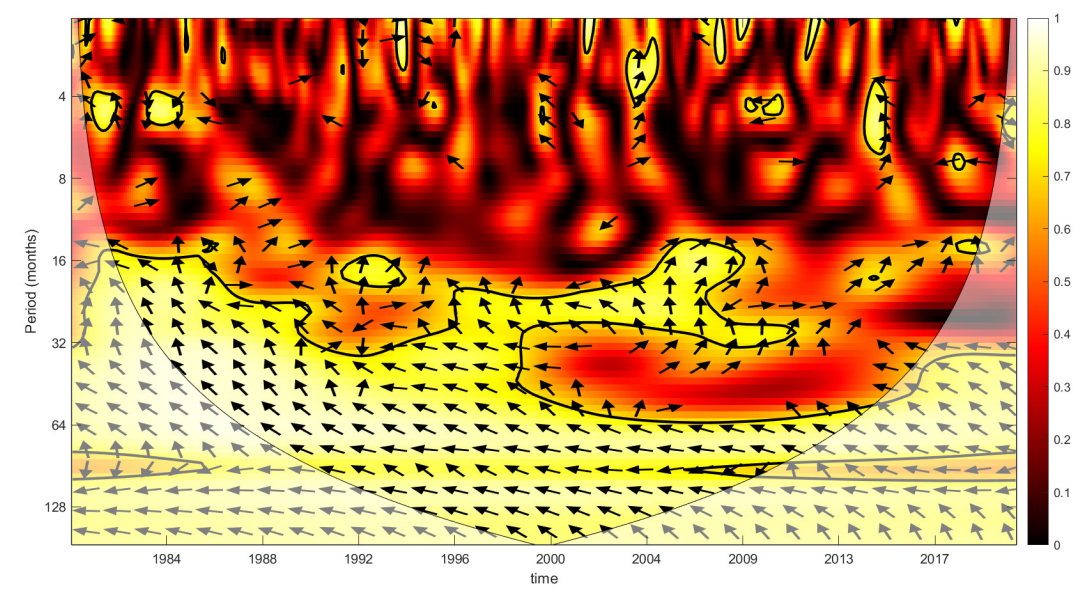

Fig. 7 - Wavelet coherence between MEI and SPI-12. The color scale on the right side of the figure represents the level of correlation between ENSO and long-term meteorological drought/pluvial events over the central highlands of West Papua. The light yellow color indicates high correlations among the variables, while the thick black contour designates the $5 \%$ significance level against red noise and the cone of influence (COI) where edge effects might distort the picture is shown as a lighter shade. The arrows show the phasing direction (right: in-phase, left: anti-phase, down: MEI leading SPI-12 by $\pi / 2$, up: SPI-12 leading MEI by $\pi / 2$ ).

As seen in Figure 7, WTC can capture the negative relationship between MEI and SPI-12 at 32 to 128 month periodicity. This causal effect reveals that precipitation over the central highlands of West Papua increases during La Niña and decreases during El Niño.

\section{ENSO - SPI-12 DYNAMIC RELATIONSHIP AND PREDICTABILITY}

In order to produce accurate SPI-12 predictions, we use Nonlinear Autoregressive with Exogenous input neural networks (NARX) model to capture the dynamic

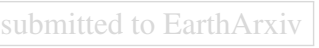


relationship between ENSO and long-term drought/pluvial events over the central highlands of West Papua. NARX is a type of recurrent dynamic neural networks that is widely used to model nonlinear relationships from attributes in a time series [28-30]. A simple NARX diagram can be seen in Figure 8. Inputs are entered into delay units, which act as memory for the previous inputs. The outputs from NARX are also stored in delay units, which are then entered directly into hidden units.

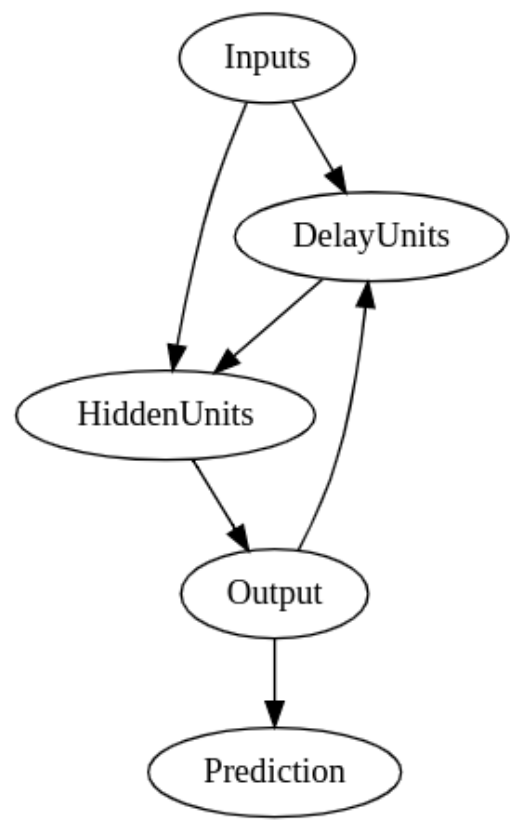

Fig. 8 - Simple schematic diagram of NARX model.

NARX model is defined as a nonlinear mapping function $f$ [28] as follows,

$$
y_{t}=f\left(y_{t-1}, y_{t-2}, \cdots, y_{t-d_{y}}, x_{t-1}, x_{t-2}, \cdots x_{t-d_{x}}\right)
$$

, where $y$ is a target (SPI-12) and $x$ are attributes (MEI); and $d_{x} \geq 1, d_{y} \geq 1, d_{y} \geq$ $d_{x}$ are delays. The nonlinear $f$ function itself is generally unknown, and must be approximated using the existing data. There are various ways to approximate this function, in this study we use multilayer perceptrons provided by PyNeurGen library [31] in the Python computational environment. We use 1 time steps of delay for each of the input (x) and output (y) attributes. In addition, we also split incoming weights, $60 \%$ for MEI and $30 \%$ for SPI-12. We make use of the following sigmoid function for activation of the perceptrons,

$$
S(x)=\frac{1}{1+e^{-x}}
$$


We divided SPI-12 into two parts, $85 \%$ for the training set and $15 \%$ (January 1980 December 2014) for the testing set (January 2015 - December 2020). We use a moderate steps of learning rate of $35 \%$ for the optimization process using the Stochastic Gradient Descent (SGD) algorithm. Our NARX model is run for 10 epochs without activating the random testing parameter to maintain the order of time-series data. To evaluate the model performance, we use the Mean Squared Error (MSE) which is shown by equation (22) below,

$$
M S E=\frac{1}{n} \sum_{i=1}^{n}\left(\hat{y}_{i}-y_{i}\right)^{2}
$$

, which is the sum series of the squared differences of the observed target $y_{i}$ and predicted values $\hat{y}_{i}$, which is then divided by the total number of test samples $n$. The MSE at each training epoch can be seen in Figure 9. It exhibits sharp decline at the first epoch and finally leveling out until the end of the last training epoch. The

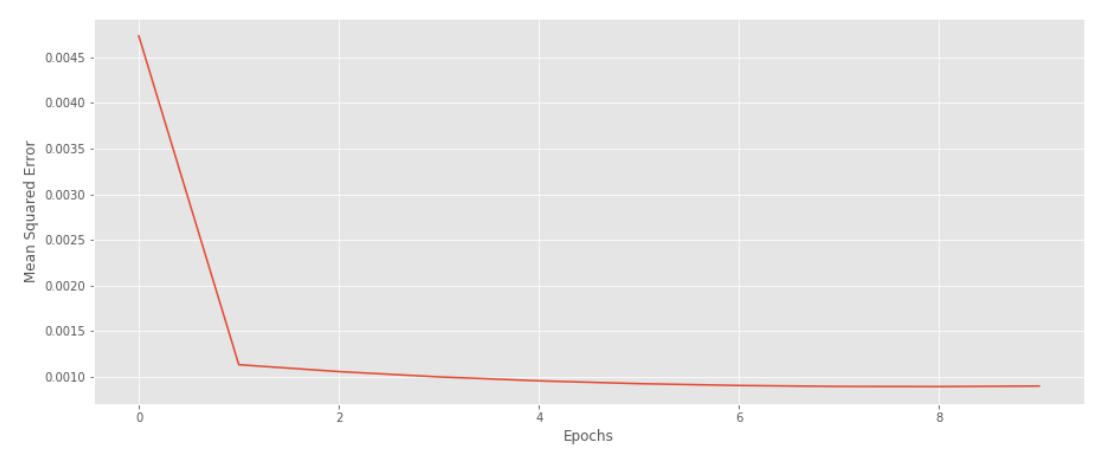

Fig. 9 - MSE by epoch for NARX model.

overall MSE evaluation result in the test set is 0.011341 . The comparison between the NARX model prediction results and the actual SPI-12 is shown in Figure 10. Overall, the model tends to overestimate and underestimate certain extreme values, although it adequately captures the general pattern of SPI- 12 .

\section{CONCLUDING REMARKS AND FUTURE WORK SUGGESTIONS}

We have performed time series analysis of the SPI-12 over the central highlands of West Papua. We found time series teleconnection pattern between ENSO and hydrometeorological drought / pluvial events in this region through wavelet transformations. Our result suggests that ENSO is negatively correlated to the long-term rainfall 


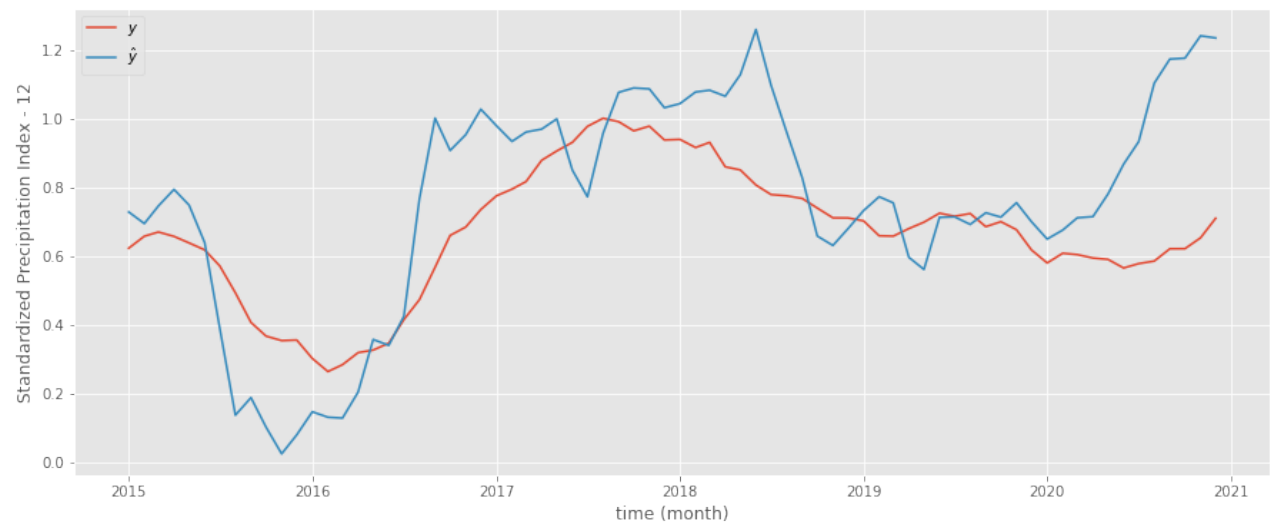

Fig. 10 - Actual $y$ (red) and predicted $\hat{y}$ (blue) SPI-12 values for NARX model.

pattern in this region. We use the patterns we obtained from the WTC to model the temporal dynamics between ENSO - long-term rainfall patterns using the NARX algorithm. The prediction results from the NARX model that we use can capture the general pattern of the underlying dynamics of SPI-12.

The study suggests possible extension of the work by using different fine-tuned optimization schemes on the NARX model [32] and using early-stopping algorithms [33] to avoid training overfitting. In addition, a comparison of more powerful seq2seq machine learning algorithms such as Long-Short Term Memory (LSTM) [34], Gated Recurrent Unit (GRU) [35], and DeepAR [36] is also needed to select the time-series model that best represents the data. Comparison and data assimilation with Global Climate Model (GCM) outputs is also needed to understand the physical process of the spatio-temporal dynamics between ENSO and long-term rainfall patterns over the central highlands of West Papua.

Acknowledgments. The author is indebted many thanks to Cristy Q. Ho and Michael N. Evans for fruitful discussion and critics in preparing the article. The author also thanks Dasapta E. Irawan for sharing the computational resource to run the statistical models. The author gratefully thank Herho Group Corp., Rialto, CA for the financial support. The code and datasets used for this work are posted on GitHub at https://github.com/sandyherho/tsHydrochWP.

\section{REFERENCES}

1. C. J. Pigram and P. A. Symonds, "A review of the timing of the major tectonic events in the new guinea orogen," Journal of Southeast Asian Earth Sciences, vol. 6, no. 3, pp. 307-318, 1991.

2. T. R. Charlton, "Tertiary evolution of the eastern indonesia collision complex," Journal of Asian Earth Sciences, vol. 18, no. 5, pp. 603-631, 2000.

3. D. B. Dow and R. Sukamto, "Western irian jaya: The end-product of oblique plate convergence in the late tertiary," Tectonophysics, vol. 106, no. 1, pp. 109-139, 1984. 
4. C. S. Ramage, "Role of a tropical "maritime continent" in the atmospheric circulation," Monthly Weather Review, vol. 96, no. 6, pp. 365 - 370, 1968.

5. C.-P. Chang, Z. Wang, J. McBride, and C.-H. Liu, "Annual cycle of southeast asia-maritime continent rainfall and the asymmetric monsoon transition," Journal of Climate, vol. 18, no. 2, pp. $287-301,2005$.

6. J. Boerema, Van Den Typen Regenval in Nederlandsch Indie (Rainfall types in Nederlands Indies). The Royal Observatory Magnetisch En Meteorologisch Batavia, Batavia, 1938.

7. D. S. Permana, L. G. Thompson, and G. Setyadi, "Tropical west pacific moisture dynamics and climate controls on rainfall isotopic ratios in southern papua, indonesia," Journal of Geophysical Research: Atmospheres, vol. 121, no. 5, pp. 2222-2245, 2016.

8. A. Marshall and B. M. Beehler, The Ecology of Papua, vol. 1. Singapore: Periplus Editions (HK), 2007.

9. B. Goger, M. W. Rotach, A. Gohm, I. Stiperski, and O. Fuhrer, "Current challenges for numerical weather prediction in complex terrain: Topography representation and parameterizations," in 2016 International Conference on High Performance Computing Simulation (HPCS), pp. 890-894, 2016.

10. M. D. Yamanaka, "Physical climatology of indonesian maritime continent: An outline to comprehend observational studies," Atmospheric Research, vol. 178-179, pp. 231-259, 2016.

11. C. D. Peters-Lidard, M. Clark, L. Samaniego, N. E. C. Verhoest, T. van Emmerik, R. Uijlenhoet, K. Achieng, T. E. Franz, and R. Woods, "Scaling, similarity, and the fourth paradigm for hydrology," Hydrology and Earth System Sciences, vol. 21, no. 7, pp. 3701-3713, 2017.

12. H. Hersbach, B. Bell, P. Berrisford, S. Hirahara, A. Horányi, J. Muñoz-Sabater, J. Nicolas, C. Peubey, R. Radu, D. Schepers, A. Simmons, C. Soci, S. Abdalla, X. Abellan, G. Balsamo, P. Bechtold, G. Biavati, J. Bidlot, M. Bonavita, G. De Chiara, P. Dahlgren, D. Dee, M. Diamantakis, R. Dragani, J. Flemming, R. Forbes, M. Fuentes, A. Geer, L. Haimberger, S. Healy, R. Hogan, E. Hólm, M. Janisková, S. Keeley, P. Laloyaux, P. Lopez, C. Lupu, G. Radnoti, P. de Rosnay, I. Rozum, F. Vamborg, S. Villaume, and J. Thépaut, "The era5 global reanalysis," Quarterly Journal of the Royal Meteorological Society, vol. 146, no. 730, pp. 1999-2049, 2020.

13. P. Wessel, J. F. Luis, L. Uieda, R. Scharroo, F. Wobbe, W. H. F. Smith, and D. Tian, "The generic mapping tools version 6," Geochemistry, Geophysics, Geosystems, vol. 20, no. 11, pp. 5556-5564, 2019.

14. T. B. McKee, N. J. Doesken, and J. Kleist, "The relationship of drought frequency and duration of the time scales," in Proceeding 8th Conference on Applied Climatology, (Anaheim, CA), American Meteorological Society, 1993.

15. N. B. Guttman, "Accepting the standardized precipitation index: A calculation algorithm1," Journal of the American Water Resources Association, vol. 35, no. 2, pp. 311-322, 1999.

16. S. Herho, M. R. Syahputra, and R. Suwarman, "A preliminary study of meteorological drought influences to social events over the maritime continent during the last millennium," in Extended Abstract 98th American Meteorological Society Annual Meeting, 16th History Symposium, (Austin, TX), American Meteorological Society, 2018.

17. S. S. P. Shen and R. C. J. Somerville, Climate Mathematics: Theory and Applications. Cambridge University Press, 2019.

18. S. Hoyer and J. Hamman, "xarray: N-D labeled arrays and datasets in Python," Journal of Open Research Software, vol. 5, no. 1, 2017.

19. E. Aldrian and R. D. Susanto, "Identification of three dominant rainfall regions within indonesia and their relationship to sea surface temperature," International Journal of Climatology, vol. 23, no. 12, pp. 1435-1452, 2003. 
20. G. M. Guenang and F. M. Kamga, "Computation of the standardized precipitation index (spi) and its use to assess drought occurrences in cameroon over recent decades," Journal of Applied Meteorology and Climatology, vol. 53, no. 10, pp. 2310 - 2324, 2014.

21. S. Beguería and S. Vicente-Serrano, SPEI: Calculation of the Standardised PrecipitationEvapotranspiration Index, 2017. R package version 1.7.

22. S. Yoden, S. Otsuka, N. J. Trilaksono, and T. W. Hadi, Recent Progress in Research on the Maritime Continent Monsoon, ch. Chapter 6, pp. 63-77. 2017.

23. K. Wolter and M. S. Timlin, "El niño/southern oscillation behaviour since 1871 as diagnosed in an extended multivariate enso index (mei.ext)," International Journal of Climatology, vol. 31, no. 7, pp. 1074-1087, 2011.

24. K.-M. Lau and H. Weng, "Climate signal detection using wavelet transform: How to make a time series sing," Bulletin of the American Meteorological Society, vol. 76, no. 12, pp. 2391 - 2402 , 1995.

25. C. Torrence and G. P. Compo, "A practical guide to wavelet analysis," Bulletin of the American Meteorological Society, vol. 79, no. 1, pp. 61 - 78, 1998.

26. S. Krieger, N. Freij, A. Brazhe, C. Torrence, and G. P. Compo, PyCWT: spectral analysis using wavelets in Python, 2017. Python library version 0.3.0a22.

27. A. Grinsted, J. C. Moore, and S. Jevrejeva, "Application of the cross wavelet transform and wavelet coherence to geophysical time series," Nonlinear Processes in Geophysics, vol. 11, no. 5/6, pp. 561-566, 2004.

28. E. Diaconescu, "The use of narx neural networks to predict chaotic time series," World Scientific and Engineering Academy and Society (WSEAS), vol. 3, no. 3, p. 182-191, 2008.

29. M. R. C. O. Ang, R. M. Gonzalez, and P. P. M. Castro, "Multiple data fusion for rainfall estimation using a NARX-based recurrent neural network - the development of the REIINN model," IOP Conference Series: Earth and Environmental Science, vol. 17, p. 012019, 2014.

30. J. M. Caswell, "A nonlinear autoregressive approach to statistical prediction of disturbance storm time geomagnetic fluctuations using solar data," Journal of Signal and Information Processing, vol. 5, pp. 42-53, 2014.

31. D. Smiley, PyNeurGen: Python Neural Genetic Algorithm Hybrids, 2012. Python library version 0.3.1.

32. X. He, K. Zhao, and X. Chu, "Automl: A survey of the state-of-the-art," Knowledge-Based Systems, vol. 212, p. 106622, 2021.

33. R. Gençay and M. Qi, "Pricing and hedging derivative securities with neural networks: Bayesian regularization, early stopping, and bagging," IEEE Transactions on Neural Networks, vol. 12, pp. $726-734,082001$.

34. S. Hochreiter and J. Schmidhuber, "Long Short-Term Memory," Neural Computation, vol. 9, no. 8, pp. 1735-1780, 1997.

35. F. A. Gers, J. Schmidhuber, and F. Cummins, "Learning to forget: continual prediction with lstm," in 1999 Ninth International Conference on Artificial Neural Networks ICANN 99. (Conf. Publ. No. 470), vol. 2, pp. 850-855, 1999.

36. D. Salinas, V. Flunkert, J. Gasthaus, and T. Januschowski, "Deepar: Probabilistic forecasting with autoregressive recurrent networks," International Journal of Forecasting, vol. 36, no. 3, pp. 11811191, 2020. 